\title{
留学生来华前后对中国认识差异研究一一四川师范大学为例
}

\author{
王飞华 陈洁玉 何静 \\ 四川师范大学
}

DOI:10.32629/er.v3i7.2937

\begin{abstract}
[摘 要] 本研究通过文献分析、访谈、调查问卷和数据统计等方法对四川师范大学留学生来华前后对 中国的认识差异进行调查, 调查内容主要涉及中国的气候、中国人的日常生活、性格、家庭与婚姻、中 国的经济和社会六个大的方面,并分析产生差异的原因。本论文为研究的第三部分, 主要分析留学生对中 国经济社会来华前后认知的差异。
\end{abstract}

[关键词] 来华留学生; 认识; 差异

\section{1 前期研究简介}

本论文为研究 《留学生来华前后对 中国认识差异研究——以四川师范大学 为例》的第三部分。本研究通过文献分 析、访谈、调查问卷和数据统计等方法 对四川师范大学留学生来华前后对中国 的认识差异进行调查。研究的第一部分 对于本研究的研究目标及意义、前期研 究概况、研究方法等做了较为详细的说 明。研究的第二部分调查分析了来华留 学生对于中国人的性格、婚姻及中国南 方 (四川) 的气候, 在来华前后的认识是 否有差异以及产生差异的原因。本论文 为研究的第三部分内容, 主要分析留学 生对中国经济科技社会等宏观层面来华 前后认知的差异。

\section{2 来华前后留学生有关中国的} 综合国力认知的调查

外国学者将综合国力的构成要素 确定为经济、军事、政治三方面, 具体 包括地理条件、自然资源、人口数量、 国民生产总值、工业能力、金融贸易、 科技、军备状况、民族特性、国民意志、 外交素质、政府素质。问卷的第22题至 第31题以我国综合国力的工业、科技两 方面为基础对留学生进行提问以了解 留学生来华前后对中国部分综合国力 认识的差异。

2. 1 综合国力的工业能力认知调查

问卷关于综合国力的工业能力方面 的考察设置在第 $22 、 23 、 24 、 25 、 26$ 和

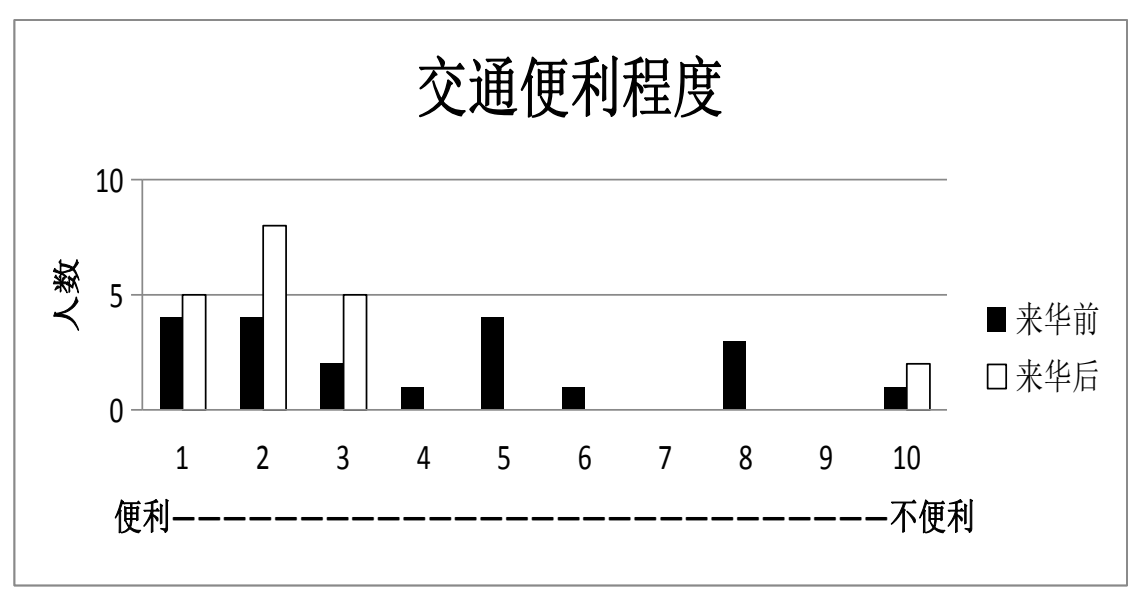

28 题。判断一个国家或地区的工业化水 平, 不仅要考察人均GDP水平, 还要考察 产业结构水平、就业结构、消费结构、 工业结构变动、外贸结构水平以及城镇 化水平等。问卷选取部分指标进行考察, 其中第 $23 、 24$ 和 26 题是考察城镇化水平 的认识, 第 25 题考察人均 GDP 水平的认 识, 第 $22 、 27$ 和 28 题考察工业结构变动 的认识。

留学生对于我国城镇化水平及公共 交通设施等持乐观的态度, 在来中国之 前, 有 $90 \%$ 的留学生认为中国的汽车和高 楼大厦很多或者较多, 这与留学生在来 中国之后的认识相一致。有 $50 \%$ 的留学生 在来中国之前认为中国交通状况便利, 而来中国之后, 认为中国交通便利的留 学生比例上升到 $90 \%$ 。自改革开放以来, 中国交通业实现了革命性跨越式的发展,
具体表现为各种交通指标不断上台阶, 交通总资本占社会总资本不断上升。中 国主要交通指标增长速度均超过发达国 家, 在全世界比重迅速增加, 已经位居世 界前列。留学生对中国交通便利程度评 价的大幅提高, 说明虽然有一定量的留 学生在来华前对中国交通发展有一定认 识, 但很显然在总体上来看, 中国交通的 便利发达程度远超出了他们的想象。

关于中国人的收入水平, 留学生的 认识差异较大。在 “很高、比较高、不 高、有的高有的不高” 四个选项中, 来中 国之前, 认为中国国民收入比较高或不 高合计占70\%, 来中国之后留学生对中国 国民收入的认识呈现多样化的特点, 但 多数人认为中国国民收入有的高有的不 高。中国已经顺利跨入中上等收入国家 行列, 而 $26 \%$ 的留学生认为中国国民收入 


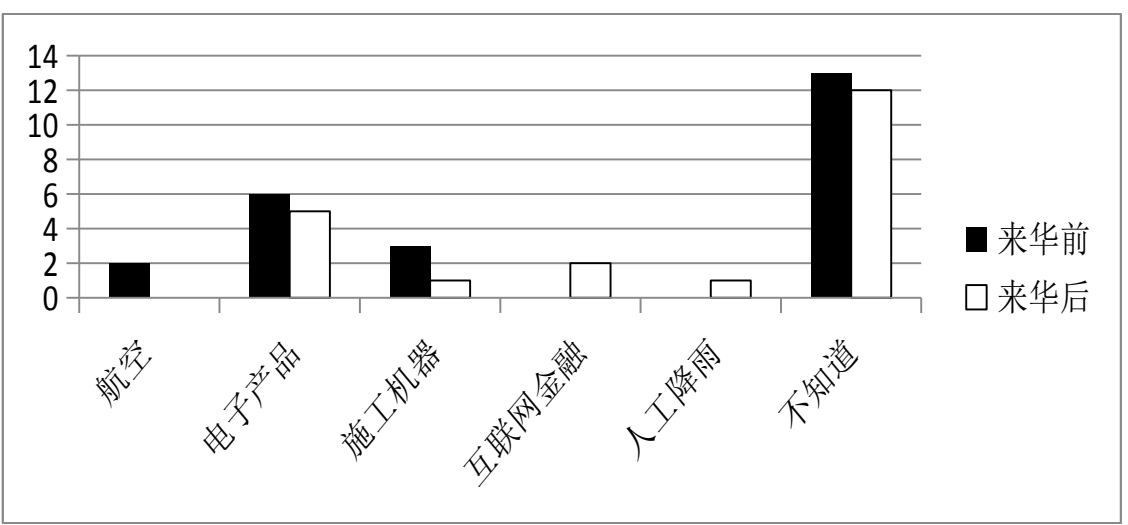

不高, $21 \%$ 的留学生认为很高, 只有 $11 \%$ 的 留学生选择了处于中间选项的比较高。

这些差异性选择其实反映了我国现 阶段发展的一个特点。总体上来说, 我国 人民的收入水平已经达到了一个很高的 水平, 但人均来看, 并不是非常理想。贫 富差距还较大, 东西部收入差距也很明 显, 城市和偏远乡村的收入差距也没有 得到根本改观。因此, 留学生基于他所看 到的某些实际情况, 就会做出相应的选 择判断。

留学生对于中国产业工业化的认识 有些不足。我国当前工业结构的工业化 水平, 大致处于由重工业化阶段向高加 工度化阶段逐步推进的时期, 亦即工业 化进入中期阶段。在来中国前, $60 \%$ 的留 学生认为中国商品大部分或全部由手工 制作, 即手工工业占比重最大。在来中国 之后, $58 \%$ 的留学生认为中国商品大部分 由机器制作, 但其余 $42 \%$ 的留学生仍认为 中国商品大部分或全部由手工制作。留 学生常见的中国产品主要为生活用品和 电子产品, 其中电子产品以小米品牌最 为出名, 留学生认为中国主要生产的产 品与他们常见的中国产品一致, 这两者 的一致程度集中表现在电子产品和生活 用品上。综合来看, 留学生对中国产业工 业化的认识有些不足, 这也体现了我国 正处在由传统工业向高加工度工业的转 型期。

\section{2 综合国力的科技方面}

问卷关于综合国力的科技方面的考 察设置在第30、31题。

$60 \%$ 以上的留学生表示不清楚中国 的高科技产品, $20 \%$ 左右的留学生认为中
国的高科技产品是电子产品。留学生对 中国的高科技产品认识很不全面, 这与 我国高科技产品的推广方面有较大联 系。在我国高科技产品出口结构中, 计算 机与通讯技术类产品占了很大比重, 具 有较强的贸易竞争力, 其他技术类产品 的出口份额比较小, 不具有贸易竞争力。 基于这一事实, 留学生对我国高科技产 品认识不足是有理可循的。

结合综合国力的工业能力和科技两 方面的考察, 留学生对中国综合国力的 认识在来华前后较为一致, 但在科技和 产品产业方面的认识无论来华前后都存 在较大空白。这说明我国对综合国力的 方面宣传力度需要加强。

\section{3 留学生来华前后对中国社会} 现象的认识情况

调查问卷的 $18 、 32 、 33 、 34 、 35$ 和 36 题是考查留学生对中国社会其中一些 部分的了解, 包括热点问题、特有政策和 比较有名的事件等, 题目的形式有选择 题和问答题, 通过对有效问卷中留学生 的回答进行分析得出以下结论。

3. 1 来华前留学生对中国社会的 认识

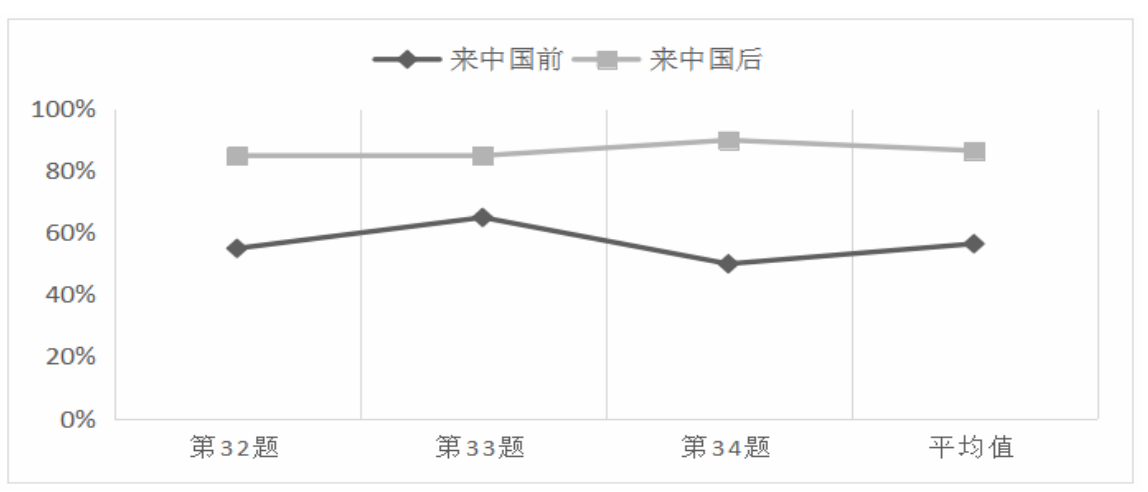

18: $60 \% ; 35: 25 \% ; 36: 60 \%$; 平均 值: $48.3 \%$

由此可以看出, 来中国之前, 对中国 特有政策和比较有名的事件有 $56.6 \%$ 的 留学生是知道的, 也就是说, 大部分留学 生在来中国之前对中国社会的一些现象 有一些基本的认识; 来中国之前, 留学生 对中国宗教和一些热点问题的认识比较 符合中国实际情况的人数占 $48.3 \%$ 。总体 来看, 留学生在来中国之前对中国社会 现象的认识程度没有对中国家庭婚姻的 认识程度高。

3. 2来中国之后留学生对中国社会 的认识

来中国后, 对于特有政策及著名事 件, 留学生知道的百分比, 各题分别为:

32: $85 \%$; 33: $85 \%$; 34: $950 \%$; 平 均值: $86.6 \%$

对于有关宗教及热点问题的几道题, 留学生认知符合中国实际情况的各题百 分比为:

18: $90 \%$; $35: 10 \% ; 36: 55 \%$; 平均 值: $51.6 \%$

将来华前后的数据用折线图反映如 下:

对于特有政策及著名事件, 有 32 、 33、34三道题, 这三道题分别是考查留学 生是否知道中国举办过奥运会, 是否知 道中国的计划生育以及是否知道“打工” 是什么意思。留学生知道的百分比, 各题 分别为:

32 : $55 \%$; $33: 65 \% ; 34: 50 \%$; 平均 值: $56.6 \%$

对于有关宗教及热点问题的几道题, 留学生认知符合中国实际情况的各题百 分比为: 
从折线图中可以看出, 对中国特有 政策和比较有名的事件, 留学生知道人 数的百分比来中国后有明显的增加, 说 明有更多的留学生在来中国之后了解了 中国特有政策和比较有名的事件。通过 访谈我们了解到留学生知道这些的主要 途径是老师上课的讲述以及互联网。对 比可以看出, 留学生在 18 题宗教上来华 后认识符合中国实际的百分比与来华前 相比有很大的提升, 说明有更多留学生 在来中国以后对中国的宗教有了一个比 较正确的认识, 但是也存在一部分留学 生只知道中国是有宗教的, 并不知道中 国具体有哪些宗教。

\section{4 调查结论与启示}

结合我们所做的全部调查, 我们的 总结及启示如下:

(1) 留学生对华认识有前后保持 一致的方面, 但这种一致有的符合实 际, 有些则始终不准确。如有关中国家 庭婚姻、南方气候、日常生活的认识, 这些认识基本上前后一致且符合实
际。但留学生对中国工业能力和科技 的认识虽然前后也较一致, 但认识一 直存在偏差。这一点尤其表现在对我 国高科技发展的认识上, 留学生对我 国科技发展存在认识空白。

(2) 留学生来华前后对中国人的性 格认识差异较大, 但这种差异总体上主 要是向正面转变。留学生对中国人性格 的总体印象趋向为中国人友好、努力、 诚实、爱笑和内向, 这种改变主要是受到 了解中国的渠道、与中国人的交往程度 等因素的影响。

调查的启示:

(1) 针对留学生来华前对中国认识 有误解的部分, 中国应加大自我宣传, 通 过电视、电影、新闻媒体等多种渠道, 纠正其误解。

(2) 针对来华后留学生仍有误解的 部分, 汉语老师在课堂上予以正确地引 导, 汉语教材的编写上可以对留学生容 易出现认知偏差的部分进行知识普及。

(3) 适当根据留学生的情况, 设计时
事热点的教学内容, 让留学生能够更好 地了解新时代的新中国。

(4) 鼓励在校留学生更多地与中国 学生接触交流, 通过与中国学生的相处 与沟通, 更直接全面地了解中国人的性 格、日常生活、婚姻家庭等。

\section{[参考文献]}

[1]邓禹.广西东盟留学生对中国形 象的认知与启示 [D].暨南大学,2012.

[2] 赵利缘.广州非洲留学生心目中 的中国形象 [D].暨南大学,2014.

[3]韩瑞玲,路紫.中国综合国力的增 长及其国际比较 [J]. 山东师范大学学报 (自然科学版),2008(2):77-80.

[4]王敏,黄港.中国的环境污染与经 济增长[J].经济学(季刊),2015(1):5.

[5]鞍钢,童旭光,王亚华.当代中国 交通发展: 一场静悄悄的革命[J].湖南社 会科学,2010(1):47-52.

[6]张震龙,姜爱林.中国工业化 水平的综合考察 [J]. 工业工程与管 理,2005(6):1-7. 